\title{
A AFIRMAÇÃO DO DIREITO INTERNACIONAL PÚBLICO EM CONTEXTOS DE CRISE GLOBAL
}

\author{
THE AFFIRMATION OF INTERNATIONAL LAW IN CONTEXTS OF GLOBAL CRISIS
}

\author{
Pedro Bohomoletz de Abreu Dallari*
}

\begin{abstract}
Resumo:
A reflexão acadêmica em torno do impacto, para a sociedade mundial, da crise decorrente da disseminação global do novo coronavírus (Sars-CoV-2) e da doença por ele causada (Covid-19) tem levado a diversos e distintos cenários imaginados para a pós-pandemia. Por meio da consideração da evolução histórica de seu acervo normativo e de seus institutos, o direito internacional público apresenta elementos que podem contribuir para essa reflexão. Uma das decorrências das crises globais tem sido justamente a afirmação do direito internacional público como ambiente privilegiado para a fixação de paradigmas voltados a orientar a sociedade mundial na reconfiguração de seu funcionamento, em um contexto inexorável de maior integração. Na sequência de cada crise global - dado o impacto geograficamente amplo da crise e a necessidade de se lograr, face ao risco a ela imanente, estabilidade na ordem internacional -, deram-se, para além de qualquer motivação idealista, o fortalecimento do multilateralismo e a expansão do direito internacional público. A aferição dessa correlação pode ser feita pela análise das transformações vivenciadas pelo direito internacional público na esteira tanto de crises globais generalizadas, marcadas pelo colapso da segurança internacional, como de crises globais tópicas, da qual é exemplo a crise sanitária desencadeada pela pandemia da Covid-19. A compreensão do risco para a estabilidade mundial que esta pandemia acarreta fará com que importantes temas que ficaram estagnados nos últimos anos - o aquecimento global, a vulnerabilidade social, as assimetrias na economia internacional - tenham que voltar à pauta de negociação de um multilateralismo renovado, gerando novo impulso na evolução do direito internacional público.
\end{abstract}

Palavras-chave: Direito Internacional. Direito Internacional Público. Crise global. Pandemia. Covid-19.

\begin{abstract}
:
Academic studies on the impact, for the world society, of the crisis resulting from the global spread of the new coronavirus (Sars-CoV-2) and the disease caused by it (Covid-19) has led to several and different scenarios imagined for the post-pandemic.
\end{abstract}

Pedro Bohomoletz de Abreu Dallari é, desde 2013, Professor Titular de Direito Internacional do Instituto de Relações Internacionais da Universidade de São Paulo (USP), do qual foi vice-diretor e diretor. Na USP, é ainda professor do Programa de Pós-Graduação da Faculdade de Direito, à qual esteve vinculado funcionalmente de 2002 a 2013, coordena o Centro Ibero-americano (CIBA) e a Cátedra José Bonifácio e é membro da Comissão de Direitos Humanos. Exerceu, no Brasil e no exterior, diversas funções públicas, tendo sido, entre outras atribuições, juiz e presidente do Tribunal Administrativo do Banco Interamericano de Desenvolvimento (BID, 2004 a 2008), membro do Conselho Diretor do Centro de Estudos de Justiça das Américas, órgão da Organização dos Estados Americanos (CEJA-OEA, 2012 a 2017) e coordenador e relator da Comissão Nacional da Verdade (CNV, 2013 e 2014). 
Considering the historical evolution of its rules and doctrine, International Law presents elements that can contribute to these studies. One of the consequences of most global crisis has been precisely the affirmation of the International Law as a privileged space for setting paradigms that lead world society in reconfiguring its functioning, in an inexorable context of greater integration. Following each global crisis - given the geographically wide impact of the crisis and the risk to the stability of the international order - there was, beyond any idealistic motivation, the strengthening of multilateralism and the expansion International Law. The finding of this correlation can be made by analyzing the transformations experienced by International Law in the wake of both generalized global crises, characterized by the collapse of international security, and specific global crises, of which the health crisis triggered by the Covid-19 pandemic is an example. The understanding of the risk to world stability that this pandemic entails will mean that important issues that have stagnated in recent years - global warming, social vulnerability, asymmetries in the international economy - will have to return to the agenda of a renewed multilateralism, generating a new movement in the evolution of International Law.

Keyword: International Law. Public International Law. Global crisis. Pandemic. Covid-19.

\section{Introdução}

A reflexão acadêmica em torno do impacto, para a sociedade mundial, da crise decorrente da disseminação global do novo coronavírus (Sars-CoV-2) e da doença por ele causada (Covid-19) tem levado a diversos e distintos cenários imaginados para a pós-pandemia. As previsões oscilam desde a previsão de mudanças abruptas - nos campos político, econômico e social - até a de mero retorno à situação anterior à crise. Essa variedade não implica, necessariamente, contraposição. Conforme a perspectiva e os critérios adotados na análise, as mudanças que poderão advir irão se materializar em maior ou menor grau, impondo-se, para a tentativa de se conceber um quadro mais consistente, a conveniência de se buscar subsídios fornecidos por diferentes áreas do conhecimento.

Por meio da consideração da evolução histórica de seu acervo normativo e de seus institutos, o direito internacional público apresenta elementos que podem contribuir para essa reflexão, sendo um dos mananciais a ser obrigatoriamente adotado na produção de análises que se pretendam mais abrangentes. Isto porque, uma das decorrências das crises globais tem sido justamente a afirmação do direito internacional público como ambiente privilegiado para a fixação de paradigmas voltados a orientar a sociedade mundial na reconfiguração de seu funcionamento. Não se trata da identificação de uma relação causal com características uniformes que possam elevá-la à condição de lei inexorável das ciências sociais, já que, na sequência de cada crise global, as transformações do direito internacional não observam comandos regulares e uniformes. Mas, há, indiscutivelmente, um padrão no fato de que, em contextos de crise global, o 
direito internacional público se modifica e se afirma como fator relevante na reformulação das normas de convivência da sociedade mundial.

O entendimento do que seja uma crise global não se presta à simplificação. Aqui, também, diferentes perspectivas e critérios podem acarretar distintas conclusões. À luz do direito, uma possibilidade bastante aceitável é dar essa qualificação a situação que, ocasionando, em escala planetária, acentuada instabilidade nas relações políticas, econômicas e sociais, enseje modificação significativa da ordem jurídica, consubstanciada por intermédio de normas de direito internacional público. Em que pese a existência de antecedentes do século XIX que podem sugerir pontualmente esse enquadramento sendo exemplo a adoção da primeira Convenção de Genebra e a emergência do direito internacional humanitário na década de 1860, em contraposição ao terrível impacto provocado pelo intenso aprimoramento tecnológico do material bélico -, a Primeira Guerra Mundial, entre 1914 e 1918, é o marco que configura uma crise global em sentido pleno, na sua feição de evento extremo quanto ao alcance geográfico e à abrangência dos efeitos (políticos, econômicos e sociais), sendo a celebração do Tratado de Versalhes e a criação da Sociedade das Nações (SdN), em 1919, consequências que assinalaram o advento de uma ordem jurídica de vocação planetária.

Com efeito, por força fundamentalmente dos significativos avanços da pesquisa científica e da tecnologia, o início do século $\mathrm{XX}$ vivenciou a rápida acentuação e consolidação da interatividade no plano mundial, em dinâmica que não mais cessou e que, por decorrência, vem promovendo, desde então, a progressiva adoção de normas de direito internacional público voltadas à regência não só da coexistência dos Estados, mas da própria vida social. De regramento voltado basicamente à fixação de fronteiras e ao estabelecimento de alianças militares ofensivas e defensivas, destinadas, na essência, a manter ou a alterar fronteiras, o direito internacional público passou a versar sobre matérias até então adstritas ao direito produzido pelo Estado, complementando e mesmo substituindo as normas nacionais. Nesse cenário de crescente integração internacional, ensejador do fenômeno da globalização - independentemente das múltiplas acepções que o termo encerra -, as crises, muitas vezes, assumiram escala global. ${ }^{1} \mathrm{E}$, assim, como se deu ao final da Primeira Guerra Mundial, os contextos de crise global se prestaram a promover, com respaldo no incremento das relações multilaterais, o adensamento e o fortalecimento do direito internacional público, acelerando processo que já resultava natural, de proliferação de uma normatividade jurídica internacional.

Expressão simbólica dessa simultaneidade da crescente integração internacional com a emergência de crises globais é a coincidência da deflagração da Primeira Guerra Mundial, em setembro de 1914, com o início efetivo da atividade do Canal do Panamá, então recentemente inaugurado e que possibilitou a circunavegação terrestre em rota mais próxima à linha do Equador, contribuindo significativamente para o incremento do comércio internacional. 
$\mathrm{Na}$ sequência de cada grande crise global - justamente pelo impacto geograficamente amplo da crise e pela necessidade de, face ao risco a ela imanente, se lograr estabilidade na ordem internacional -, deram-se, para além de qualquer motivação idealista, o fortalecimento do multilateralismo e a expansão do direito internacional público, como expressão jurídica de medidas de políticas públicas adotadas em um contexto inexorável de maior integração global. A aferição desse quadro pode ser feita pela análise das transformações vivenciadas pelo direito internacional público na esteira tanto de crises globais generalizadas, marcadas pelo colapso da segurança internacional, como de crises globais tópicas, da qual é exemplo a crise sanitária desencadeada pela pandemia da Covid-19. É o que se fará a seguir, com respaldo basicamente em documentos normativos internacionais, abordando-se, ao final, alguns aspectos substantivos e formais presentes nesse movimento evolutivo.

2. A afirmação do direito internacional público em contextos de crise global generalizada

Com mais de 20 milhões de mortos, entre combatentes e população civil, com impacto em todas as áreas da atividade humana e em todos os continentes, a Primeira Guerra Mundial (1914 a 1918) foi superada pela Segunda Guerra (1939 a 1945), ainda mais destrutiva e de maior magnitude, com o número de mortos superando 70 milhões. São as duas crises generalizadas que marcaram o mundo globalizado. E tiveram grande impacto na transformação do direito internacional público e na conformação do direito contemporâneo.

Celebrado em 28 de junho de 1919, na França, no palácio que lhe forneceu a denominação, o Tratado de Versalhes assinalou o encerramento da Conferência de Paz de Paris e, indo além da mera repactuação entre as potências beligerantes na então denominada Grande Guerra, buscou estabelecer diretrizes para a governança da vida mundial. ${ }^{2}$ As disposições iniciais do Tratado de Versalhes são dedicadas ao Pacto que criou a Sociedade das Nações (SdN), organização internacional inédita na abrangência de seu escopo e afiliação, voltada justamente à implementação dessas diretrizes. ${ }^{3}$ Muito

$2 \quad$ Na obra Tratado de Versalhes na história do direito internacional, Paulo Borba Casella (2007) faz uma apresentação detalhada daquele diploma normativo internacional, salientando a inovação que representou na conformação do direito internacional público.

3 A Sociedade das Nações (tradução da versão em francês, adotada oficialmente no Brasil) ou Liga das Nações (tradução da versão em inglês, bastante utilizada na produção acadêmica brasileira) foi instituída por meio do Pacto da Sociedade das Nações, que se constitui na parte inicial do Tratado de Versalhes, adotado em 28 de junho de 1919. O Brasil foi signatário do tratado e o ratificou em 10 de janeiro de 1920, dando-se a promulgação por via do Decreto n. 13.990, de 12 de janeiro do mesmo ano. O país tornou-se, assim, Estado membro daquela organização internacional, situação que perdurou até 1926, quando dela se 
embora a organização não mais exista e seja vista, de modo geral, como uma experiência mal sucedida - constituída principalmente com a finalidade de evitar a deflagração de um conflito de proporções globais como aquele que, iniciado em 1914, havia se encerrado no final do ano anterior, a Segunda Guerra Mundial significou o fracasso desse intento fundamental e conduziu à sua própria extinção ${ }^{4}$-, a $\mathrm{SdN}$ correspondeu ao primeiro ato significativo voltado à configuração do conjunto das coletividades humanas existentes no planeta como uma comunidade juridicamente delineada, regida por princípios e mecanismos institucionais formalmente estabelecidos. ${ }^{5} \mathrm{O}$ tratado e a organização internacional por ele constituída abrigaram iniciativas muito relevantes em favor do aperfeiçoamento e da universalização de regras mais justas para o convívio social. É o caso, entre muitos exemplos possíveis, da legislação protetiva dos trabalhadores, já enunciada no tratado e desenvolvida e sistematizada a partir de órgão que, situado no interior da SdN, veio a se tornar a Organização Internacional do Trabalho (OIT).

A constituição da $\mathrm{SdN}$ não significou ruptura com a lógica estrutural que presidira até então a configuração do direito internacional público, fundada essencialmente na ação soberana dos Estados e cuja materialização se expressava na necessidade do consentimento para a caracterização de obrigação jurídica no plano das respectivas relações exteriores. A estruturação do direito internacional público sobre essa base é comumente identificada na doutrina com os tratados de paz celebrados na Vestefália em 1648, que puseram fim às guerras religiosas do período e consagraram a perspectiva de edificação da ordem política europeia a partir do funcionamento de um sistema de Estados soberanos, superando-se a tutela pretendida especialmente pela Igreja Católica. ${ }^{6}$

retirou. A presença brasileira na organização é retratada em detalhes na obra O Brasil e a Liga das Nações (1919-1926), de Eugênio Vargas Garcia. (GARCIA, 2005).

4 Em obra bastante abrangente dedicada à apresentação da história dos trabalhos da Conferência de Paz de Paris, a pesquisadora da Universidade de Oxford e professora da Universidade de Toronto Margaret Macmillan registra essa percepção acerca do fracasso da SdN: "So great was the taint of failure that when the powers contemplated a permanent association of nations during the Second World War, they decided to set up a completely new United Nations. The League was officially pronounced dead in 1946 . It had ceased to count at all in 1939". (MACMILLAN, 2003, p. 83).

5 Na obra já referida, Margaret Macmillan resgata declaração efetuada por ocasião da assembleia que pôs fim à existência da organização, em 1946, na qual o diplomata britânico Robert Cecil expressa justamente a natureza precursora da SdN (League of Nations, na versão adotada para o inglês): "At its last assembly, Lord Robert Cecil, who had been there at its creation, asked, 'Is it true that all our efforts for those twenty years have been thrown away?' He answered his own question bravely: 'For the first time an organization was constructed, in essence universal, not to protect the national interest of this or that country ... but to abolish war.' The League had been, he concluded, 'a great experiment.' It had put into concrete form the dreams and hopes of all those who had worked for peace through the centuries. It had left its legacy in the widespread acceptance of the idea that the nations of the world could and must work together for the collective security of them all. "The League is dead: Long live the United Nations"”. (MACMILLAN, 2003, p. 84).

$6 \quad$ No parágrafo 333 dos Princípios da filosofia do direito, de 1821, Georg Wilhelm Friedrich Hegel sintetiza essa perspectiva contratual do direito internacional: "333 - O fundamento do direito dos povos como direito universal que entre os Estados é válido em si e para si e que é diferente do conteúdo particular dos contratos, 
Inerente a essa lógica vestefaliana, a compreensão do Estado como o sujeito exclusivo de direito internacional público, e do costume e do tratado como suas fontes fundamentais - na medida que se associam justamente à externalização do consentimento estatal -, não foi afetada direta e expressamente pelas diretrizes estabelecidas pelo Pacto da $\mathrm{SdN}$, que, de um ponto de vista político, concebeu a organização como uma espécie de foro permanente de concertação do conjunto dos Estados, que possibilitasse a reprodução, de forma contínua, de eventos que vinham se verificando ocasionalmente, sendo os então mais recentes as Conferências de Paz realizadas na Holanda, na Haia, em 1899 e $1907 .{ }^{7}$ Como diretriz geral, não se encontrava presente, portanto, na pauta da Conferência de Paz de Paris, que originou o Tratado de Versalhes e o Pacto da SdN, a efetiva adoção de orientação supranacional para o equacionamento de temas variados de impacto internacional, especialmente em matéria de segurança, mas sim a viabilização de mecanismos que, por meio do incremento da frequência e da regularidade do relacionamento interestatal, possibilitassem a antecipação e superação das controvérsias internacionais. Notadamente os conflitos próprios da matéria até então disciplinada pelo direito internacional público, concernente, fundamentalmente, como visto, à definição das fronteiras territoriais dos Estados e, correlacionando-se a esta temática, àquela associada, mesmo que de forma implícita (acordos aduaneiros, por exemplo), à segurança e ao uso da força. ${ }^{8}$ Mesmo o tratamento conferido a normas de direito do trabalho no corpo do Tratado

reside no dever de se respeitarem os contratos, pois neles se fundam as obrigações dos Estados uns para com os outros. Como, porém, a relação entre eles tem por princípio a sua soberania, daí resulta que se encontram uns perante os outros num estado de natureza e os seus direitos não consistem numa vontade universal constituída num poder que lhes é superior, mas obtêm a realidade das suas recíprocas relações na sua vontade particular. Esta condição geral mantém-se no estado de dever ser e o que realmente se passa é uma situação de situações conformes a tais tratados e de abolições desses tratados”. (HEGEL, 1976, p. 297298).

7 As diretrizes políticas iniciais da Conferência de Paz de Paris foram estabelecidas pelo presidente norteamericano Woodrow Wilson, professor de direito público na Universidade Princeton, amparado na legitimidade internacional auferida pelos Estados Unidos em função do papel decisivo de suas tropas para o encerramento do conflito mundial. Essas diretrizes se consubstanciaram em quatorze pontos, o último deles dedicado à proposta de instituição de uma organização internacional com as finalidades que, posteriormente, viriam a ser atribuídas à SdN e que estava assim redigido: "XIV. A general association of nations must be formed under specific covenants for the purpose of affording mutual guarantees of political independence and territorial integrity to great and small states alike". (MACMILLAN, 2003, p. 496).

8 No relato que também fez sobre o evento diplomático de Paris, Jean-Jacques Becker, professor de história contemporânea na Universidade de Paris X - Nanterre, registra a evolução da negociação em torno dos poderes de que deveria a $\mathrm{SdN}$ : "A grande dificuldade encontrava-se, sobretudo, em determinar os meios de ação da SDN. [...] Finalmente, chegaram a um consenso sobre o futuro artigo 16 do Pacto. A aplicação de sanções econômicas e financeiras, decididas pelo Conselho, seria obrigatória e automática para todos os Estados membros. Mas as sanções militares ou navais, que requeriam a unanimidade do Conselho para serem deliberadas, estariam sujeitas a 'recomendações', sendo facultativa sua aplicação. Em resumo, a SDN não podia servir de real garantia aos ataques. [...] Na realidade, a SDN não possuía meios verdadeiros de ação". (BECKER, 2011, p. 156-159). 
de Versalhes não deve ser visto, a princípio, como negação dessa perspectiva, mas como mera exceção, derivada do impacto causado pelo movimento político revolucionário em curso na Rússia e da preocupação das grandes potências reunidas em Paris com que não se disseminasse.

No texto preambular do Tratado de Versalhes, introdutório do Pacto da $\mathrm{SdN}$, a reafirmação dessa perspectiva interestatal de viés contratualista, tipicamente vestefaliana, se encontra plenamente explicitada:
As altas partes contratantes,
Considerando que, para desenvolver a cooperação entre as
Nações e para lhes garantir a paz e a segurança, importa: aceitar certas obrigações de não recorrer à guerra; manter claramente relações internacionais fundadas sobre a justiça e a honra; observar rigorosamente as prescrições do direito internacional, reconhecidas de ora em diante como regra de conduta efetiva dos Governos; fazer reinar a justiça e respeitar escrupulosamente todas as obrigações dos tratados nas relações mútuas dos povos organizados;
Adotam o presente Pacto que institui a Sociedade das Nações. (BRASIL, 1920).

Apesar de indicação inicial de compromisso com valores universais, as obrigações dos Estados decorrentes do direito internacional público ficaram associadas à observância dos tratados, fonte contratual por excelência e na qual o consentimento é critério essencial de validade. Todavia, a crescente necessidade de conectividade entre os Estados em um contexto de grandes mudanças econômicas e sociais, aceleradas por avanços rápidos e significativos no campo científico e tecnológico, acabou por assegurar à estrutura orgânica instituída para a $\mathrm{SdN}$ papel mais significativo do que aquele que provavelmente fora imaginado pelos autores do Pacto que a criou. A ação inercial dessa estrutura ensejou, direta e indiretamente, a produção, em escala cada vez maior, de diretrizes comuns para o tratamento de temas os mais variados, refletindo-se em normatividade internacional direcionada a assuntos até então restritos à alçada legislativa dos Estados, iniciando-se, adicionalmente, processo que a doutrina jusinternacionalista qualifica de codificação do direito internacional público. É nesse contexto que se consolida a alteração qualitativa do direito internacional público, que evolui de mero direito de coexistência para direito de cooperação entre os Estados, de feição muito mais abrangente. Deu-se o adensamento acentuado da malha normativa internacional, que, ademais, passou a regular de forma crescentemente aprofundada temas da vida econômica e social das sociedades nacionais, fazendo surgir, inclusive, o debate teórico e prático referente à convivência 
das normas internacionais com aquelas de mesmo escopo produzidas internamente pelos Estados. $^{9}$

Assim, sem que se possa falar em uma qualidade propriamente supranacional, o direito internacional público do entre guerras vivenciou profundas transformações, cuja irreversibilidade não foi afetada nem mesmo pela incapacidade demonstrada por parte da estrutura institucional da SdN para evitar a eclosão da Segunda Guerra Mundial. Com efeito, o conflito instaurado em 1939 e que se prolongou até 1945 implicou a extinção da $\mathrm{SdN}$, mas seus desdobramentos, principalmente a criação da Organização das Nações Unidas (ONU), não significaram o retrocesso a padrões anteriores a 1919. Pelo contrário, intensificou-se a produção normativa internacional, verificando-se o advento da supranacionalidade e, mais do que isso, alteração no próprio fundamento do direito internacional público, que - em face da identificação, no plano internacional, dos direitos fundamentais do ser humano - afastou o consentimento do Estado como critério absoluto para sua existência e validade. Se, após a Primeira Guerra Mundial, a SdN significou a tentativa de estabilização da ordem internacional a partir de iniciativa que, embora formalmente inovadora, ainda fosse conduzida pelos preceitos da lógica vestefaliana, as situações extremas vivenciadas após apenas duas décadas - com o horror do Holocausto e das bombas nucleares, ${ }^{10}$ que marcaram a Segunda Guerra - aceleraram a superação daquela lógica, em processo cuja inevitabilidade já estava determinada pelo curso das transformações nas relações econômicas e sociais em âmbito global que se vinham verificando ao longo do século XX.

Fruto da Conferência das Nações Unidas sobre Organização Internacional mais conhecida como Conferência de São Francisco, cidade norte-americana que abrigou o evento -, a Carta das Nações Unidas foi celebrada em 26 de junho de 1945, antes mesmo dos ataques nucleares, quando o conflito global ainda perdurava no Extremo Oriente, e teve por propósito a constituição da ONU. ${ }^{11}$ Já no preâmbulo do documento, fica evidenciada a mudança de paradigma em relação à ordem jurídica adotada no Tratado

$9 \quad$ Hans Kelsen(1927, p. 231-331) dedicou ao assunto curso que ministrou na Academia de Direito Internacional da Haia em 1926: "Les rapports de système entre le droit interne et le droit international public".

10 Na introdução de obra dedicada à descrição dos eventos que cercaram a elaboração da Carta das Nações Unidas e a criação da ONU, Stephen C. Schlesinger, ao comparar aquele momento com outros que trataram do reordenamento das relações internacionais (os eventos de Vestefália, Viena e Versalhes), sintetiza com precisão o significado da realidade nuclear: "the founding of the United Nations, in far more sinister circumstances than faced any of the U.N.'s predecessors - namely, the age of nuclear weaponry - is affecting the survival or demise of humanity". (SCHLESINGER, 2004, p. XV).

11 A Organização das Nações Unidas (ONU) foi instituída por meio da Carta das Nações Unidas, tratado adotado em São Francisco, nos Estados Unidos, em 26 de junho de 1945. O Brasil assinou o tratado na mesma data, tendo o depósito do instrumento brasileiro de ratificação sido efetuado em 21 de setembro de 1945. A promulgação do tratado se deu também no ano de 1945, por via do Decreto n. 19.841 , de 22 de outubro. 
de Versalhes. Desse preâmbulo se extrai a primazia conferida aos direitos humanos como critério determinante na configuração da nova ordem internacional, o que vai se acentuar nos anos subsequentes com o advento da Declaração Universal dos Direitos Humanos, em 1948, e a estruturação dos sistemas internacionais de proteção aos direitos humanos. Assim está redigido esse texto inaugural:

\section{Preâmbulo}

Nós, os povos das Nações Unidas, resolvidos a preservar as gerações vindouras do flagelo da guerra, que por duas vezes, no espaço da nossa vida, trouxe sofrimentos indizíveis à humanidade, e a reafirmar a fé nos direitos fundamentais do homem, na dignidade e no valor do ser humano, na igualdade de direito dos homens e das mulheres, assim como das nações grandes e pequenas, e a estabelecer condições sob as quais a justiça e o respeito às obrigações decorrentes de tratados e de outras fontes do direito internacional possam ser mantidos, e a promover o progresso social e melhores condições de vida dentro de uma liberdade ampla.

E para tais fins, praticar a tolerância e viver em paz, uns com os outros, como bons vizinhos, e unir as nossas forças para manter a paz e a segurança internacionais, e a garantir, pela aceitação de princípios e a instituição dos métodos, que a força armada não será usada a não ser no interesse comum, a empregar um mecanismo internacional para promover o progresso econômico e social de todos os povos.

Resolvemos conjugar nossos esforços para a consecução desses objetivos.

Em vista disso, nossos respectivos Governos, por intermédio de representantes reunidos na cidade de São Francisco, depois de exibirem seus plenos poderes, que foram achados em boa e devida forma, concordaram com a presente Carta das Nações Unidas e estabelecem, por meio dela, uma organização internacional que será conhecida pelo nome de Nações Unidas. (BRASIL, 1945).

E logo nos arts. $1^{\circ}$ e $2^{\circ}$ da Carta das Nações Unidas, elencam-se propósitos e princípios, voltados a dar consequência à abordagem preambular fundada no estabelecimento de paradigmas éticos, e induzindo a uma perspectiva supranacional e à mudança do fundamento do direito internacional: 
Capítulo I - Propósitos e princípios

Artigo 1. Os propósitos das Nações Unidas são:

1. Manter a paz e a segurança internacionais e, para esse fim: tomar, coletivamente, medidas efetivas para evitar ameaças à paz e reprimir os atos de agressão ou outra qualquer ruptura da paz e chegar, por meios pacíficos e de conformidade com os princípios da justiça e do direito internacional, a um ajuste ou solução das controvérsias ou situações que possam levar a uma perturbação da paz;

2. Desenvolver relações amistosas entre as nações, baseadas no respeito ao princípio de igualdade de direitos e de autodeterminação dos povos, e tomar outras medidas apropriadas ao fortalecimento da paz universal;

3. Conseguir uma cooperação internacional para resolver os problemas internacionais de caráter econômico, social, cultural ou humanitário, e para promover e estimular o respeito aos direitos humanos e às liberdades fundamentais para todos, sem distinção de raça, sexo, língua ou religião; e

4. Ser um centro destinado a harmonizar a ação das nações para a consecução desses objetivos comuns.

Artigo 2. A Organização e seus Membros, para a realização dos propósitos mencionados no Artigo 1, agirão de acordo com os seguintes Princípios:

1. A Organização é baseada no princípio da igualdade de todos os seus Membros.

2. Todos os Membros, a fim de assegurarem para todos em geral os direitos e vantagens resultantes de sua qualidade de Membros, deverão cumprir de boa fé as obrigações por eles assumidas de acordo com a presente Carta.

3. Todos os Membros deverão resolver suas controvérsias internacionais por meios pacíficos, de modo que não sejam ameaçadas a paz, a segurança e a justiça internacionais.

4. Todos os Membros deverão evitar em suas relações internacionais a ameaça ou o uso da força contra a integridade territorial ou a dependência política de qualquer Estado, ou qualquer outra ação incompatível com os Propósitos das Nações Unidas.

5. Todos os Membros darão às Nações Unidas toda assistência em qualquer ação a que elas recorrerem de acordo com a presente Carta e se absterão de dar auxílio a qualquer Estado contra o qual as Nações Unidas agirem de modo preventivo ou coercitivo. 
6. A Organização fará com que os Estados que não são Membros das Nações Unidas ajam de acordo com esses Princípios em tudo quanto for necessário à manutenção da paz e da segurança internacionais.

7. Nenhum dispositivo da presente Carta autorizará as Nações Unidas a intervirem em assuntos que dependam essencialmente da jurisdição de qualquer Estado ou obrigará os Membros a submeterem tais assuntos a uma solução, nos termos da presente Carta; este princípio, porém, não prejudicará a aplicação das medidas coercitivas constantes do Capítulo VII. (BRASIL, 1945).

É importante registrar que disposições com o conteúdo desses arts. $1^{\circ} \mathrm{e}$ $2^{\circ}$ da Carta das Nações Unidas não figuraram no Pacto da $\mathrm{SdN}$ - cujo art. $1^{\circ}$, destinado a identificar os membros da $\mathrm{SdN}$, corresponde à matéria do art. $3^{\circ}$ da Carta das Nações Unidas -, isto pela razão já exposta de que o documento de 1919, embora tenha acarretado mudanças significativas na ordem jurídica internacional, não almejava à alteração da natureza essencialmente interestatal do direito internacional público. $\mathrm{Na}$ perspectiva adotada no Tratado de Versalhes, tendo por fundamento o consentimento dos Estados, as normas internacionais se justificariam exclusivamente por força do procedimento de elaboração, sendo irrelevante, do ponto de vista da validade jurídica, a observância de critérios de finalidade ou mesmo de princípio. Por sua vez, a concepção de ordem internacional imanente ao documento de 1945 significou alteração da concepção do Pacto da SdN, com a introdução de quadro normativo de referência contendo objetivos e princípios destinados a guiar a ação institucional da nova organização internacional, claramente a habilitando a se sobrepor à vontade dos Estados, tanto membros como não membros.

Em síntese, reconhece-se explicitamente na Carta das Nações Unidas a igualdade entre os Estados (art. $2^{\circ}, 1$ ), cuja soberania, no entanto, só é afirmada - e mesmo assim de forma vaga e relativizada - no tocante aos assuntos que dependam essencialmente da própria jurisdição (art. $2^{\circ}, 7$ ), ${ }^{12}$ impondo-se aos Estados membros o cumprimento das obrigações assumidas de acordo com a Carta (art. 2º, 2), e aos não membros agir em conformidade com as determinações da ONU associadas aos princípios

12 No já citado estudo sobre a fundação da ONU, Stephen C. Schlesinger registra que a formulação inicial para essa disposição do item 7 do art. $2^{\circ}$, efetuada ainda na Conferência preliminar de Dumbarton Oaks, de 1944, dava margem até mesmo a que coubesse ao direito internacional público a determinação dos assuntos que ficariam na alçada exclusiva dos Estados. Mas, conforme informa o professor da New School University, de Nova York, os parlamentares que integravam a delegação norte-americana na Conferência de São Francisco a isso se opuseram: "The legislators demanded that the phrase 'international law' be dropped from the clause on the grounds that it was always unpredictable in determining the proper allocation of responsibilities between states and the world community". (SCHLESINGER, 2004, p. 237-238). 
estabelecidos no tratado (art. $2^{\circ}, 6$ ). Fica explicitado, ainda, no preâmbulo da própria Carta das Nações Unidas, que as obrigações dos Estados não decorrem apenas do que venha a ser consentido por meio de tratado, como se encontrava assinalado no Tratado de Versalhes, mas também emanam de outras fontes do direito internacional público, o que amparou a progressiva utilização dos princípios de direito como fundamento dos atos internacionais. À medida, portanto, que o documento que se constitui em pedra angular da ordem jurídica internacional nega ao consentimento a condição fundamento e de critério absoluto de validade para obrigação de Estado no âmbito dessa mesma ordem, tem-se alteração substancial no plano da teoria do direito internacional público. ${ }^{13} \mathrm{E}$, em que pese a realidade das relações internacionais não ensejar a superação imediata da lógica estrutural estritamente lastreada na soberania estatal, paulatinamente, passou a se fazer cada vez mais presente a concepção delineada no tratado adotado em São Francisco para a substância e a conformação da ordem jurídica internacional, isto por força da dinâmica decorrente da intensificação das transformações econômicas e sociais já em curso mesmo por ocasião da celebração do Tratado de Versalhes.

Consequência da enorme destruição provocada pela Segunda Guerra Mundial, que ceifou milhões de vidas, a ONU significou um grande avanço em relação à $\mathrm{SdN}$. Sob a ótica da busca da estabilidade nas relações políticas, econômicas e sociais internacionais, a ONU não só estabeleceu mecanismos mais consistentes para promover a segurança internacional, como, dando seguimento, mas indo muito além da $\mathrm{SdN}$, impulsionou, para todas as áreas da vida social, a produção de um robusto quadro normativo, fixador de paradigmas universais, e a criação de organismos, inclusive tribunais, destinados a propiciar monitoramento mais efetivo da aplicação dessas normas. A Organização Mundial da Saúde(OMS), cujas atividades se iniciaram em 1948 e que ficou em grande evidência na crise global decorrente da pandemia da Covid-19, exemplifica essa evolução. ${ }^{14} \mathrm{Na}$ evolução do direito internacional público ao longo do século XX,

13 A formulação que acabou prevalecendo para o item 7 do art. $2^{\circ}$ deu margem suficiente a que o Conselho de Segurança e a Corte Internacional de Justiça, órgãos regidos pelo direito internacional público, se tornassem os intérpretes da Carta das Nações Unidas com prerrogativa para estabelecer os assuntos que "dependam essencialmente da jurisdição de qualquer Estado", o que, por exemplo, ocorreu nas decisões que negaram à África do Sul a possibilidade de aplicar o apartheid como mecanismo de regência da vida social interna. Esse entendimento é corroborado por Celso Lafer, professor da Faculdade de Direito e do Instituto de Relações Internacionais da Universidade de São Paulo: “O Artigo $2^{\circ}$, $\S 7^{\circ}$ da Carta adotou, em matéria de jurisdição interna dos Estados, em contraposição ao artigo $15, \S 8^{\circ}$ do Pacto da Sociedade das Nações, uma formulação mais dinâmica e aberta à evolução do Direito Internacional. Assim, ao invés de referir-se à 'competência exclusiva', como fez o Pacto, a carta referiu-se a assuntos que dependem essencialmente de jurisdição interna do Estado, o que, como assinalou Lauterpacht, permitiu, sob a égide da carta de São Francisco, ao Direito Internacional, ir ampliando progressivamente sua esfera de normatividade". (LAFER, 1999, p. 157).

14 A Organização Mundial da Saúde (OMS, WHO na sigla em inglês) foi criada através de tratado adotado em 22 de junho de 1946. O Brasil foi signatário do tratado e o ratificou em $1^{\text {o }}$ de junho de 1948, dando-se a 
quanto à sua caracterização, do direito de coexistência passou-se, com a ordem política instaurada com a SdN, para o direito de cooperação entre os Estados, e deste se vem avançando, a partir da ordem política inaugurada pela ONU, na configuração do direito da comunidade humana, voltado à regência da comunidade conformada pelo conjunto dos seres humanos. ${ }^{15}$

E nem mesmo o quadro de bipolaridade da guerra fria, que marcou as relações internacionais por cerca de quatro décadas - conferindo a dois Estados, os Estados Unidos da América (EUA) e a União das Repúblicas Socialistas Soviéticas (URSS), papel dirigente na condução da vida internacional -, evitou que fosse sendo erguido, paulatinamente, um vasto arcabouço jurídico de instituições, princípios e regras claramente fundados na perspectiva da supranacionalidade. ${ }^{16}$ Com o fim desse contexto de bipolaridade, o processo teve sequência com vigor ainda maior, registrando-se não só o contínuo adensamento desse arcabouço, mas sua crescente sistematização, não sendo adequado se transpor de forma automática, para o campo da ordem jurídica internacional - que associa o direito internacional público à dinâmica de aproximação, e mesmo

promulgação por via do Decreto n. 26.042, de 17 de dezembro de 1948. A OMS é decorrência das iniciativas multilaterais voltadas ao equacionamento internacional de assuntos de saúde pública que já se verificavam há algumas décadas, sendo marco relevante o Código Sanitário Internacional de 1926, justamente do período do entre guerras.

15 Pierre-Marie Dupuy propõe para a caracterização do direito internacional público abordagem articuladora de três diferentes perspectivas, que, valendo-se de terminologia de uso disseminado na doutrina jusinternacionalista, denomina, respectivamente, "droit de la coexistence", "droit de la coopération" e "droit de la communauté internationale et de l'humanité". (DUPUY, 2006, p. 24). O professor da Universidade de Paris II (Pantheón-Assas) adota tais perspectivas como dimensões que convivem no direito internacional público contemporâneo. Já neste artigo, elas se encontram referidas com significado diverso, mais precisamente para indicar a qualidade essencial do direito internacional público sob o prisma de sua evolução histórica, como qualificações que se sucedem e substituem, sendo, portanto, excludentes. Nesse sentido, muito embora regras internacionais de coexistência e cooperação entre Estados continuem a ser produzidas em grande escala, elas o são no contexto de um direito internacional que se pode qualificar como direito da comunidade humana, pois tem como unidade sistêmica básica o ser humano e por fundamento a condição jurídica universalmente identificada para o ser humano de titular de direitos fundamentais.

16 No curso geral de direito internacional público que ministrou em 1999 na Academia de Direito Internacional da Haia, Christian Tomuschat observou justamente que as diferenças ideológicas da Guerra Fria não comprometeram a força expansiva do direito internacional: "The socialist doctrine of international law could to some extent be termed a constructive attempt to secure peaceful relations during the period of cold war. Contrary to opinions expressed by a considerable number of Western writers, it did not deny the existence of obligatory legal bonds between the two antagonistic groups of States. And in fact, the thesis of an unbridgeable gap permitting of no common juridical element between capitalism and socialism was an exaggeration hardly borne out by realities. East and West did cooperate in order to ensure at least a minimum level of common ground even during periods of sharp political tensions". (TOMUSCHAT, 1999, p. 34). Corroborando esse entendimento, pode-se registrar que o principal tratado internacional concernente à garantia do uso pacífico do espaço cósmico - o Tratado sobre princípios reguladores das atividades dos Estados na exploração e uso do espaço cósmico, inclusive a lua e demais corpos celestes - foi celebrado em Moscou, em 1967. 
uniformização, dos direitos nacionais -, a noção de fragmentação, que tem marcado a cena política internacional nos anos recentes. ${ }^{17}$

3. A afirmação do direito internacional público em contextos de crise global tópica

Sem desconsiderar o papel determinante que as crises globais generalizadas - associadas, como se viu, ao colapso do quadro de segurança internacional - tiveram no desenvolvimento estrutural do direito internacional público, crises de alcance igualmente global, mas de caráter tópico, também acabaram por impulsionar o multilateralismo e por promover avanços reais no plano da normatividade internacional. Crises econômicas, sociais, ambientais, sanitárias, como a da pandemia da Covid-19, deram ensejo à aceleração desse movimento. E é certo que tais crises, mesmo consideradas tópicas, por estarem associadas a causas bastante específicas, geram efeitos que transcendem essas particularidades e terminam repercutindo em outras dimensões - de natureza sanitária, a crise da Covid-19 tem gerado impacto de grande magnitude na economia internacional, entre outras áreas. Isso faz com que o efeito das crises globais tópicas sobre o direito internacional público acabe por afetar diversas de suas especialidades.

Mesmo sem se promover o tratamento exaustivo da matéria, o resgate de algumas crises globais tópicas é suficiente para evidenciar essa associação com a evolução e afirmação do direito internacional público. E, dada a centralidade que apresenta em nossa época, o âmbito da saúde global se presta a fornecer exemplos expressivos, como aquele relacionado à Declaração sobre o Acordo TRIPS e Saúde Pública, adotada pela Conferência Ministerial da Organização Mundial do Comércio (OMC) em Doha, no Catar, em 2001. ${ }^{18}$ Mais conhecido na doutrina do direito internacional sanitário pela fórmula simplificada Declaração de Doha, o documento, embora faça referência a outras doenças (como tuberculose e malária), resultou especialmente da crise gerada pela rápida disseminação, na década de 1990, da AIDS (sigla em inglês de síndrome da imunodeficiência adquirida, SIDA), doença causada pelo vírus da imunodeficiência humana (HIV, na sigla em inglês) e que, assumindo a dimensão de uma pandemia (termo

17 Visão antagônica à bastante disseminada perspectiva de fragmentação do direito internacional público está exposta pelo autor em artigo publicado em 2017: "The integration of the law in a politically fragmented world" (DALLARI, 2017). Cabe salientar que o tema da fragmentação do direito internacional público foi objeto de análise por parte da Comissão de Direito internacional da ONU, que produziu o relatório intitulado Fragmentation of International Law: Difficulties Arising From the Diversification and Expansion of International Law, datado de 13 de abril de 2006, cujas conclusões, apesar de apontarem obstáculos, identificam claro viés integracionista para o quadro normativo internacional.

18 Declaração sobre o Acordo TRIPS e Saúde Pública, ou, na versão oficial em espanhol, Declaración relativa al acuerdo sobre los ADPIC y la salud pública, ou, ainda, na versão oficial em inglês, Declaration on the TRIPS Agreement and Public Health (ORGANIZACIÓN MUNDIAL DEL COMERCIO, 2011). 
que justamente qualifica a propagação de doença em escala global), ocasionou mais de 32 milhões de mortes no mundo, segundo dados da OMS de 2019. Instituída em 1994, no contexto de movimento em favor da adoção de regras voltadas à expansão do comércio internacional, a OMC tem na Conferência Ministerial sua instância suprema, a quem compete adotar decisões sobre todos os assuntos compreendidos nos acordos multilaterais de comércio. ${ }^{19}$

Com a qualidade formal de ato de organização internacional (International Institutional Law, como qualifica a doutrina norte-americana ${ }^{20}$ ), modalidade de fonte cuja relevância crescente é um dos aspectos marcantes da estrutura do direito internacional público contemporâneo, a Declaração de Doha objetivou assegurar aos Estados membros da OMC a preponderância da atenção com a saúde pública no cotejo com direitos de propriedade intelectual concernentes à produção de medicamentos, decorrentes do Acordo sobre Aspectos dos Direitos de Propriedade Intelectual Relacionados ao Comércio (Acordo sobre os ADPIC, ou Acordo TRIPS, como é mais conhecido na literatura acadêmica brasileira, que se vale da sigla em inglês do documento). Com base, claramente, no princípio da primazia dos direitos humanos, emanado da Carta das Nações Unidas e de todo o desenvolvimento normativo que a ela se seguiu, os cinco parágrafos iniciais do documento de 2001 fixaram orientação bastante inovadora para o direito internacional público:

1. Reconocemos la gravedad de los problemas de salud pública que afligen a muchos países en desarrollo y menos adelantados, especialmente los resultantes del VIH/SIDA, la tuberculosis, el paludismo y otras epidemias.

2. Recalcamos la necesidad de que el Acuerdo sobre los Aspectos de los Derechos de Propiedad Intelectual relacionados con el Comercio (Acuerdo sobre los ADPIC) de la OMC forme parte de la acción nacional e internacional más amplia encaminada a hacer frente a estos problemas.

3. Reconocemos que la protección de la propiedad intelectual es importante para el desarrollo de nuevos medicamentos. Reconocemos asimismo las preocupaciones con respecto a sus efectos sobre los precios.

19 A Organização Mundial do Comércio (OMC, WTO na sigla em inglês) foi criada por meio da Ata Final que Incorpora os Resultados da Rodada Uruguai de Negociações Comerciais Multilaterais do GATT, tratado conhecido como Acordo de Marraquexe, adotado em 12 de abril de 1994. O Brasil foi signatário do tratado e o ratificou em 21 de dezembro de 1994, tendo a promulgação ocorrido por meio do Decreto n. 1.355, de 30 de dezembro do mesmo ano.

20 Essa qualificação conceitual está presente em obra do professor da Universidade Columbia José Alvarez (2006). 
4. Convenimos en que el Acuerdo sobre los ADPIC no impide ni deberá impedir que los Miembros adopten medidas para proteger la salud pública. En consecuencia, al tiempo que reiteramos nuestro compromiso con el Acuerdo sobre los ADPIC, afirmamos que dicho Acuerdo puede y deberá ser interpretado y aplicado de una manera que apoye el derecho de los Miembros de la OMC de proteger la salud pública y, en particular, de promover el acceso a los medicamentos para todos.

A este respecto, reafirmamos el derecho de los Miembros de la OMC de utilizar, al máximo, las disposiciones del Acuerdo sobre los ADPIC, que prevén flexibilidad a este efecto.

5. En consecuencia, y a la luz del párrafo 4 supra, al tiempo que mantenemos los compromisos que hemos contraído en el Acuerdo sobre los ADPIC, reconocemos que estas flexibilidades incluyen:

a) Al aplicar las normas consuetudinarias de interpretación del derecho internacional público, cada disposición del Acuerdo sobre los ADPIC se leerá a la luz del objeto y fin del Acuerdo tal como se expresa, en particular, en sus objetivos y principios.

b) Cada Miembro tiene el derecho de conceder licencias obligatorias y la libertad de determinar las bases sobre las cuales se conceden tales licencias.

c) Cada Miembro tiene el derecho de determinar lo que constituye una emergencia nacional $\mathrm{u}$ otras circunstancias de extrema urgencia, quedando entendido que las crisis de salud pública, incluidas las relacionadas con el VIH/SIDA, la tuberculosis, el paludismo y otras epidemias, pueden representar una emergencia nacional $\mathrm{u}$ otras circunstancias de extrema urgencia.

d) El efecto de las disposiciones del Acuerdo sobre los ADPIC que son pertinentes al agotamiento de los derechos de propiedad intelectual es dejar a cada Miembro en libertad de establecer su propio régimen para tal agotamiento sin impugnación, a reserva de las disposiciones de los artículos 3 y 4 sobre trato NMF y trato nacional. ${ }^{21}$

${ }_{21}$ Declaración relativa al acuerdo sobre los ADPIC y la salud pública (ORGANIZAÇÃO MUNDIAL DO COMÉRCIO). Não existindo versão oficial do documento na língua portuguesa, adota-se neste artigo a redação dada às disposições do documento na versão oficial produzida pela OMC no idioma espanhol. 
Essa orientação da OMC, emanada no contexto da crise global da pandemia da AIDS, contribuiu decisivamente para a fixação da diretriz de prevalência do interesse público em matéria de saúde. Mesmo que se possa questionar a dificuldade de efetivação das medidas de implementação dessa orientação, explicitadas nos parágrafos 6 e 7, como a produção de medicamentos com licenciamento compulsório e a obrigação de transferência de tecnologia dos Estados membros mais desenvolvidos para aqueles com menor desenvolvimento, consagrou-se, em relação à área de saúde pública, a aplicação plena do princípio da prevalência dos direitos humanos. ${ }^{22}$ A Declaração de Doha, ao parametrizar, por via de interpretação, os efeitos da aplicação do Acordo TRIPS em matéria de saúde pública, veio, assim, a ter grande importância para a legitimação da adoção generalizada de políticas públicas relacionadas à produção de medicamentos genéricos, à universalização do acesso a medicamentos essenciais e mesmo, por via indireta, a outras matérias correlacionadas, como a regulação da atividade de contratação de seguro de assistência à saúde, entre outras. $\mathrm{Na}$ abordagem desse tema, a doutrina jurídica brasileira confere realce à Declaração de Doha como fonte na conformação do balizamento jurídico nacional. $^{23}$

No âmbito do direito internacional público, essa derivação para o campo da regulação econômica que se verificou com a adoção, na crise global da pandemia da AIDS, de medida jurídica internacional inovadora por parte da $\mathrm{OMC}$, também marca a reação à crise global da pandemia da Covid-19. Naturalmente, o protagonismo nessa recente crise sanitária, entre as instituições regidas pelo direito internacional público, cabe à OMS, cuja atuação tem respondido às competências que lhe foram juridicamente estabelecidas. Mas, provavelmente, a iniciativa que pode assinalar uma mudança de paradigma também

22 Em dissertação de mestrado defendida em 2006 na Faculdade de Direito da Universidade de São Paulo, Carlos Alberto Polonio faz um apanhado bastante abrangente sobre o impacto da Declaração de Doha, enfatizando sua presença em uma série de iniciativas multilaterais voltadas justamente à promoção do direito à saúde como expressão maior da afirmação dos direitos humanos. Nesse contexto, sublinha o caráter inovador do documento na revisão do alcance do direito de propriedade intelectual: "Com essa Declaração produziu-se uma interpretação autêntica do acordo TRIPS que tem força para afastar quaisquer dúvidas quanto aos reais objetivos e princípios orientadores do Acordo, criando uma regra de hierarquia dos objetivos do direito internacional da propriedade intelectual apoiada na premissa de que o 'Acordo pode e deverá ser interpretado e aplicado de uma maneira que apoie o direito dos Membros da OMC de proteger a saúde pública e, em particular, de promover o acesso aos medicamentos para todos' (parágrafo $4^{\circ}$ ). Nesse sentido, houve uma mudança substancial na interpretação do TRIPS, uma vez que o artigo 8.1 do Acordo mandava que as medidas de proteção à saúde pública fossem consistentes com o acordo TRIPS e não o contrário". (POLONIO, 2006, p. 195).

23 Abordagem doutrinária em que se reconhece a incidência da Declaração de Doha no ambiente jurídico e regulatório brasileiro pode ser constatada em referência efetuada por Patrícia Luciane de Carvalho, especialista em direito de propriedade intelectual, sobre atribuições da Agência Nacional de Vigilância Sanitária (Anvisa) em matéria de medicamentos: “à Anvisa compete a proteção da saúde pública por meio dos direitos da propriedade intelectual, inclusive com conhecimento das flexibilidades existentes no TRIPS e na Declaração de Doha”. (CARVALHO, 2020, p. 101). 
é de teor econômico e, do mesmo modo, encontra-se fundada na primazia dos direitos humanos, tendo sido adotada em julho de 2020 pela União Europeia. Com a finalidade de promover a recuperação dos Estados membros e de suas populações, severamente afetados pela pandemia da Covid-19, a União Europeia adotou medida inovadora em sua configuração e amplitude, ao decidir pela contratação, em seu próprio nome, de empréstimos nos mercados de capitais. Podendo se consubstanciar por meio da emissão de títulos da dívida pública ou de outras formas de contratação, trata-se de conduta própria da política econômica dos Estados ou da atuação de organizações internacionais estritamente financeiras, mas não de uma organização internacional de natureza e finalidade políticas. Sob a perspectiva da teoria do direito internacional público, tem-se, nitidamente, reforço significativo da diretriz de supranacionalidade, que caracteriza o estágio mais avançado dos processos de integração internacional.

Revestindo-se da condição formal de ato de organização internacional, a decisão foi tomada pelo Conselho Europeu, principal instância de orientação política da União Europeia, que reúne os chefes de Estado ou de Governo dos 27 Estados membros e da qual também participam, embora sem direito a voto, os presidentes do próprio Conselho e da Comissão Europeia. Aprovado por unanimidade ao final de reunião extraordinária daquele órgão colegiado realizada entre 17 e 21 de julho de 2020, o documento de conclusões consagrou o que qualificou como "um esforço específico de recuperação ao abrigo do Instrumento de Recuperação da União Europeia (Next Generation EU)" ${ }^{24} \mathrm{Na}$ primeira parte das conclusões, está delineada essa inciativa, a qual o Conselho Europeu, explicitando sua excepcionalidade, atribui caráter "substancial, direcionado e limitado no tempo" (UNIÃO EUROPEIA, 2020, p. 2). Os parágrafos iniciais dessa primeira parte - intitulada justamente Next Generation EU, denominação que sugere fundamentação marcadamente ética para o programa de recuperação - são expressivos na vocalização desse entendimento:

\begin{abstract}
A1. O caráter excecional da situação económica e social decorrente da crise da COVID-19 exige medidas excecionais para apoiar a recuperação e a resiliência das economias dos Estados-Membros.
\end{abstract}

A2. O plano para a recuperação da Europa exigirá um enorme investimento público e privado a nível europeu, por forma a colocar firmemente a União numa trajetória de recuperação sustentável e resiliente, criando postos de

\footnotetext{
24 As passagens do documento aqui transcritas são expressão fidedigna do que foi decidido, já que, sendo a língua portuguesa um dos idiomas utilizados formalmente pela União Europeia, é ela adotada, na forma vigente em Portugal, para a produção dos documentos oficiais da organização internacional. (UNIÃO EUROPEIA, 2020, p. 1).
} 
trabalho e reparando os danos imediatos causados pela pandemia de COVID-19, e apoiando simultaneamente as prioridades ecológicas e digitais da União. O QFP [Quadro Financeiro Plurianual], reforçado pelo Next Generation EU, será o principal instrumento europeu.

A3. A fim de dotar a União dos meios necessários para enfrentar os desafios da pandemia de COVID-19, a Comissão [Comissão Europeia] será autorizada a contrair empréstimos em nome da União nos mercados de capitais. O produto será transferido para programas da União em conformidade com o Next Generation EU.

A4. Dado que o Next Generation EU constitui uma resposta excecional a essas circunstâncias temporárias mas extremas, os poderes conferidos à Comissão para contrair empréstimos são claramente limitados em termos de dimensão, duração e âmbito.

A5. Relativamente ao Next Generation EU, a Decisão Recursos Próprios autoriza a Comissão a contrair empréstimos nos mercados de capitais em nome da União até ao montante de 750 mil milhões de EUR, a preços de 2018; qualquer nova atividade líquida de contração de empréstimos cessará o mais tardar no final de 2026. A União deve utilizar os fundos dos empréstimos contraídos nos mercados de capitais com o objetivo exclusivo de fazer face às consequências da crise da COVID-19.

A6. Os fundos dos empréstimos contraídos podem ser utilizados para conceder empréstimos até um montante de 360 mil milhões de EUR, a preços de 2018, e para despesas até um montante de 390 mil milhões de EUR, a preços de 2018. (UNIÃO EUROPEIA, 2020, p. 2-3).

Os desdobramentos dessa decisão é que revelarão o grau de sua profundidade e de seu impacto na reformulação dos procedimentos de governança internacional. De todo modo, fica evidenciado, também no contexto da crise global da pandemia da Covid-19, cenário que exibe a presença marcante e renovada de mecanismos de direito internacional público, que, por sua vez, se converte em plataforma hábil para viabilização de respostas por parte da sociedade mundial. Se a centralidade da crise gerada pela propagação do novo coronavírus remete aos casos de crise global sanitária aqui expostos, ${ }^{25}$ cabe observar, todavia, que, em crises materialmente diversas, essa tendência de afirmação do direito

25 Os casos aqui apresentados não constituem rol exaustivo no âmbito do direito internacional sanitário, podendo se assinalar que, já em 2012, a professora Deisy de Freitas Lima Ventura havia defendido, no Instituto de Relações Internacionais da Universidade de São Paulo, tese de livre-docência relacionada a outra crise sanitária de dimensão global. (VENTURA, 2012). 
internacional público também vem se apresentando. Assim, podem ser buscadas situações reveladoras dessa perspectiva em crises globais econômicas, ambientais, humanitárias, de toda matéria, enfim.

No plano ambiental, o descontrole sobre o impacto crescente a avassalador da ação humana amparada em evolução tecnológica acelerada, verificado a partir da segunda metade do século XX, conduziu a um número crescente de situações de desequilíbrio no ecossistema terrestre, algumas delas revestidas do caráter de crise de alcance global. Esse quadro fez com que, em processo contínuo e de intensidade crescente, o direito internacional do meio ambiente emergisse como especialidade do direito internacional público e o direito ao meio ambiente equilibrado e sustentável fosse alçado à condição de direito fundamental do ser humano. ${ }^{26}$ Tendo como marco inaugural mais visível a Conferência das Nações Unidas sobre o Meio Ambiente Humano, realizada em Estocolmo, na Suécia, no ano de 1972, esse processo evolutivo gerou a produção no direito internacional público, no espaço de poucas décadas, de um número expressivo de tratados e atos internacionais, bem como a institucionalização de órgãos e mecanismos de monitoramento ambiental. A crise ambiental do aquecimento global é, indiscutivelmente, uma das de maior relevância na nossa época, com repercussão sobre todas as áreas da vida humana. E, mesmo com sucessivos impasses na adoção de políticas públicas internacionais que sejam plenamente eficazes para debelar a crise, há, desde a aprovação da Convenção-Quadro das Nações Unidas sobre Mudança do Clima, em 1992, ${ }^{27}$ uma evolução, disseminando-se na sociedade internacional sentimento de urgência que pode viabilizar a alteração positiva de quadro que implica risco para as condições de sobrevivência de parcela significativa da população mundial.

Situação ambiental crítica, de amplitude global e que gerou uma resposta bastante eficaz do direito internacional público, é a que se refere à proteção da camada de ozônio da atmosfera, responsável pela preservação da superfície terrestre dos efeitos de substâncias nocivas de emissão solar prejudiciais à vida humana e ao meio ambiente. Medições realizadas na década de 1980 apontaram a crescente degradação da camada de ozônio, identificando-se como causa principal a ação dos chamados gases CFC (clorofluorcarbonetos), presentes, até então, de forma amplamente disseminada, em

\footnotetext{
26 A descrição desse processo evolutivo foi realizada pelo autor em artigo publicado em 2009: Desenvolvimento sustentável em favor da justiça social no Brasil. (DALLARI, 2009).

27 A Convenção-Quadro das Nações Unidas sobre Mudança do Clima foi adotada em 9 de maio de 1992 , sendo seguida por dois tratados adicionais de grande relevância, o Protocolo de Quioto, adotado em 11 de dezembro de 1997 e o Acordo de Paris, adotado em 12 de dezembro de 2015. O Brasil é parte dos três tratados, que foram promulgados, respectivamente, através do Decreto n. 2.652 , de $1^{\circ}$ de julho de 1998 , do Decreto n. 5.445, de 12 de maio de 2005, e do Decreto n. 9.073, de 5 de junho de 2017.
} 
equipamentos de refrigeração e sistemas de aerossol. Ainda na mesma década, dois tratados, a Convenção de Viena para a Proteção da Camada de Ozônio, de 1985, e, em aditamento a essa Convenção, o Protocolo de Montreal sobre Substâncias que Destroem a Camada de Ozônio, de 1987, ${ }^{28}$ estabeleceram normas e medidas que se revelaram bastante eficazes no equacionamento da crise. Relacionados à preocupação com o aquecimento global e de ampla aceitação por parte dos Estados, os documentos tiveram impacto imediato na transformação da tecnologia, com o afastamento dos fatores de risco. ${ }^{29}$

As crises globais tópicas de diferentes matérias têm acarretado, de forma constante, implicações para a economia internacional, gerando iniciativas de equacionamento que contemplam medidas jurídicas voltadas a essa área, como se pode constatar nos casos aqui aludidos. Sem prejuízo dessa correlação mais geral, as crises globais tópicas de escopo estritamente econômico também são responsáveis por inovações importantes na substância e na formalização do direito internacional público. Um exemplo significativo são os denominados acordos de Basileia, destinados à regulamentação bancária e aprovados em 1988, 2004 e 2010, sob os auspícios do Banco de Compensações Internacionais (BIS, na sigla em inglês, correspondente a Bank for International Settlements), organização internacional que, na sua feição atual, articula a atividade dos bancos centrais dos Estados membros. ${ }^{30}$ Produzidos em função de quadros de instabilidade econômica global - o terceiro acordo, Basileia III, surgiu em resposta à crise financeira de 2008, cujo impacto na economia internacional foi de extrema profundidade -, esses acordos, aprovados na forma de atos de organização internacional, acabaram por ter significativa influência na regulamentação dos sistemas bancários nacionais.

Outras matérias poderiam ser trazidas a exame. As crises humanitárias, por exemplo, têm sido importante motor para a instituição e aprimoramento de instrumentos jurídicos internacionais de proteção aos direitos humanos. Essa correspondência entre crises globais tópicas e iniciativas de afirmação do direito internacional público voltadas à sua superação pode ser constatada, como já foi observado, nas mais diversas situações. Os casos aqui examinados prestam-se a evidenciar um padrão correlacional que tem

28 A Convenção de Viena para a Proteção da Camada de Ozônio foi adotada em 22 de março de 1985 e o Protocolo de Montreal sobre Substâncias que Destroem a Camada de Ozônio em 16 de setembro de 1987. O Brasil ratificou os dois tratados em 19 de março de 1990, tendo a promulgação ocorrida em 6 de junho do mesmo ano, por meio do Decreto n. 99.280.

29 A Convenção de Viena para a Proteção da Camada de Ozônio foi adotada em 22 de março de 1985 e o Protocolo de Montreal sobre Substâncias que Destroem a Camada de Ozônio em 16 de setembro de 1987. O Brasil ratificou os dois tratados em 19 de março de 1990, tendo a promulgação ocorrido em 6 de junho do mesmo ano, através do Decreto n. 99.280.

30 O Brasil é Estado membro do Banco de Compensações Internacionais (BIS), organização internacional criada na década de 1930 e que exerceu diferentes atribuições ao longo de sua história. A adesão do Brasil ao Convênio Constitutivo do Banco de Compensações Internacionais se deu em 1997, tendo o tratado sido promulgado por meio do Decreto n. 3.941, de 27 de setembro de 2001. 
caracterizado a história do mundo globalizado e que não pode ser desconsiderado na avaliação dos possíveis desdobramentos dos graves problemas e desafios contemporâneos.

4. Conclusão: alguns aspectos substantivos e formais da afirmação do direito internacional público em contextos de crise global

As transformações no direito internacional público resultantes das crises globais, sejam crises generalizadas ou crises tópicas, fazem ressaltar alguns aspectos de ordem substantiva e formal, aqui brevemente descritos, a título de conclusão deste artigo. Assim como há um padrão na relação entre crises globais e a afirmação do direito internacional público, verificam-se alguns elementos comuns a esses diferentes processos conjunturais de renovação jurídica.

Em relação à substância das mudanças derivadas da afirmação do direito internacional público em contextos de crise global, um primeiro aspecto constante diz respeito à consideração dos direitos humanos como critério informador dos processos de produção normativa. As crises globais, independentemente de sua conformação, tendem a acentuar a vulnerabilidade social, o que impõe aos movimentos de reformulação jurídica a observância do conjunto de princípios e regras de proteção aos direitos humanos que vem sendo progressivamente edificado internacionalmente, inclusive como fator de legitimação e eficácia dos novos ditames que se pretenda adotar para o direito internacional público. Desde o início do século XX e, especialmente, a partir da constituição da ONU, os direitos humanos se converteram no conteúdo fundamental da ordem pública internacional, sendo inescapável sua adoção para a validação dos processos de aggiornamento jurídico.

Um segundo elemento comum inerente à substância dos movimentos de resposta do direito internacional público em contextos de crise global se reflete em dinâmica que consiste na identificação e aceleração da implementação de formulações já concebidas anteriormente. $\mathrm{O}$ que os processos de reformulação jurídica promovem, na maioria dos casos, é o resgate de experiências advindas de situações pontuais, adotandoas como regra geral. A diretriz de bem-estar social mundial que se constitui no norte das regras e atividades da ONU resulta basicamente da transposição, para o plano global, de orientação já presente na gestão de diversos Estados desde meados do século XIX. Na mesma linha, ao relativizar direitos de propriedade intelectual em favor da priorização da saúde pública, a Declaração de Doha consagrou soluções que já vinham sendo aplicadas no âmbito interno de alguns Estados. Assim, os processos de afirmação do direito internacional público em contextos de crise global são marcadamente evolutivos, com atributos até mesmo incrementais.

Finalmente, no tocante à forma desses processos transformadores do direito internacional público, cabe constatar que estes se valem de uma diversidade 
de instrumentos. Se mudanças mais abrangentes, como aquelas decorrentes das crises globais generalizadas consubstanciadas nas duas guerras mundiais, implicaram a edição de tratados de amplo espectro temático e a instituição de robustas organizações internacionais para execução e monitoramento das diretrizes normativas, isso não ocorre em todas as situações. Como se pode verificar nos casos examinados neste artigo, alguns processos foram pautados pela inovação por meio de atos de organizações internacionais. E, paradoxalmente, há processos de mudança que, espontâneos ou estimulados por modelos estabelecidos internacionalmente (qualificados pela doutrina como soft law), ${ }^{31}$ podem até mesmo prescindir de instrumentos formais de direito internacional público, dando-se através da uniformização dos direitos nacionais, em movimento passível de configuração, a posteriori, de regra costumeira ou princípio internacional. ${ }^{32} \mathrm{Com}$ a maior complexidade do quadro de instituições internacionais, a tendência é que, cada vez mais, as mudanças decorram de uma combinação de diferentes procedimentos de reformulação jurídica.

Tais aspectos substantivos e formais devem ser objeto de consideração face à crise global causada pelo novo coronavírus e pela Covid-19. Como indica o caminho já iniciado pela União Europeia, que aqui foi objeto de enfoque, a compreensão do risco para a estabilidade mundial que a crise acarreta fará com que importantes temas que ficaram estagnados nos últimos anos - o aquecimento global, a vulnerabilidade social, as assimetrias na economia internacional - tenham que voltar à pauta de negociação de um multilateralismo renovado, gerando novo impulso na evolução do direito internacional público.

São Paulo, agosto de 2020.

31 Segundo José Augusto Fontoura Costa, "faz sentido distinguir radicalmente o direito uniforme como resultado de uma aproximação espontânea de conteúdos dos diversos direitos e o derivado de uma implementação intencional - voltada a um objetivo". Para o professor da Faculdade de Direito da Universidade de São Paulo, a "uniformidade espontânea não parte de um comando básico, mas do assemelhamento dos modos de produção - não raro resultante da intensificação do contato entre sociedades diversas - ou da aglomeração de comunidades: é, portanto, resultado de transformações sociais.". Já o "direito uniforme intencional, por seu turno, engloba o direito uniforme criado com base em tratados internacionais e na atividade de organizações internacionais, assim como o direito comunitário europeu e os direitos federais". (COSTA, 2000, p. 29).

32 O jurista de origem iraniana radicado na França Djamchid Momtaz, ao analisar argumentação jurídica adotada pelo Tribunal Penal para a ex-Iugoslávia para aplicar direito nacional dos Estados como fonte para suas decisões - alegou-se que a uniformidade normativa dos direitos estatais em matéria penal permitiria identificar um costume internacional -, salientou esse fenômeno do resgate do costume como fonte relevante do direito, fazendo alusão à referência, surgida na doutrina francesa, à formula "coutume à grande vitesse" (cujas iniciais, "cgv", parodiam a sigla TGV, indicativa de "train a grand vitesse", o trem-bala francês): “C'est à juste titre qu'on a parlé de la naissance d'un nouvel univers, principalement sous l'effet de la formation d'une 'coutume à grande vitesse"”. (MOMTAZ, 2001, p. 43). 


\section{Referências}

ALVAREZ, José Enrique. International organizations as law-makers. Oxford: Oxford University Press, 2006.

BECKER, Jean-Jacques. O Tratado de Versalhes. Tradução de Constancia Egrejas. São Paulo: Editora Unesp, 2011.

BRASIL. Decreto n. 13.990, de 12 de janeiro de 1920. Promulga o Tratado de Paz entre os países aliados, associados e o Brasil de um lado e de outro a Alemanha, assinado em Versailles em 28 de junho de 1919. Portal do Planalto, Brasília, DF, jan. 1920. Disponível em: http://www.planalto.gov. br/ccivil_03/decreto/1910-1929/D13990.htm.

BRASIL. Decreto n. 19.841, de 22 de outubro de 1945. Promulga a Carta das Nações Unidas, da qual faz parte integrante o anexo Estatuto da Corte Internacional de Justiça, assinada em São Francisco, a 26 de junho de 1945, por ocasião da Conferência de Organização Internacional das Nações Unidas. Portal do Planalto, Brasília, DF, out. 1945. Disponível em: http://www.planalto. gov.br/ccivil_03/decreto/1930-1949/D19841.htm.

CARVALHO, Patrícia Luciane de. O acesso a medicamentos e as patentes farmacêuticas na ordem jurídica brasileira. Revista CEJ, Brasília, v. 11, n. 37, p. 94-102, abr.jun. 2007. Disponível em: https://revistacej.cjf.jus.br/revcej/article/view/880/1062. Acesso em: 16 ago. 2020.

CASELLA, Paulo Borba. Tratado de Versalhes na história do direito internacional. São Paulo: Quartier Latin, 2007.

COSTA, José Augusto Fontoura. Normas de direito internacional: aplicação uniforme do direito uniforme. São Paulo: Atlas, 2000.

DALLARI, Pedro Bohomoletz de Abreu. Desenvolvimento sustentável em favor da justiça social no Brasil. In: PÁDUA, José Augusto (org.). Desenvolvimento, justiça e meio ambiente. Belo Horizonte: Ed. UFMG; São Paulo: Ed. Peirópolis, 2009. p. 254-275. Disponível em: https://www. israelpinheiro.org.br/wp-content/uploads/2016/11/desenvolvimentojusticameioambiente.pdf. Acesso em: 16 ago. 2020.

DALLARI, Pedro Bohomoletz de Abreu. The integration of the law in a politically fragmented world. In: VASCONCELOS, Álvaro (org.). Brasil nas ondas do mundo. Coimbra: Imprensa da Universidade de Coimbra, 2017. p. 41-49. Disponível em: http://www.iea.usp.br/noticias/ documentos/livro-brasil-nas-ondas-do-mundo. Acesso em: 16 ago. 2020.

DUPUY, Pierre-Marie. Droit international public. 8e. éd. Paris: Dalloz, 2006.

GARCIA, Eugênio Vargas. O Brasil e a Liga das Nações (1919-1926): vencer ou não perder. Porto Alegre: Editora da UFRGS; Brasília: FUNAG, 2005.

HEGEL, Georg Wilhelm Friedrich. Princípios da filosofia do direito. 2. ed. Lisboa: Livraria Martins Fontes, 1976. (Coleção filosofia e ensaios). 
KELSEN, Hans. Les rapports de système entre le droit interne et le droit international public. Recueil des Cours de l'Académie de Droit International de La Haye, Paris, v. 14, n. 4, p. 227-331, 1927.

LAFER, Celso. Comércio, desarmamento, direitos humanos: reflexões sobre uma experiência diplomática. São Paulo: Paz e Terra, 1999.

MACMILLAN, Margaret. Paris 1919: six months that changed the world. Nova York: Random House, 2003.

MOMTAZ, Djamchid. Le droit international humanitaire applicable aux conflits armés non internationaux. Recueil des Cours de l'Académie de Droit International de La Haye, Leiden/Boston, MA, v. 292, p. 9-146, 2001.

ORGANIZACIÓN MUNDIAL DEL COMERCIO. Declaración relativa al acuerdo sobre los ADPIC y la salud pública. Doha, 9-14 nov. 2001. Disponível em: https://www.wto.org/spanish/ thewto_s/minist_s/min01_s/mindecl_trips_s.pdf. Acesso em: 16 ago. 2020.

POLONIO, Carlos Alberto. Proteção jurídica das patentes farmacêuticas no Brasil e sua adequação ao acordo TRIPS: direito à saúde e acesso a medicamentos. 2006. 238 f. Dissertação (Mestrado) -Faculdade de Direito, Universidade de São Paulo, São Paulo, 2006.

SCHLESINGER, Stephen C. Act of creation: the founding of the United Nations. Cambridge, MA: Westview Press, 2004.

TOMUSCHAT, Christian. International law: ensuring the survival of mankind on the eve of a new century - general course on public international law. Recueil des Cours de l'Académie de Droit International de La Haye, Leiden/Boston, MA, v. 281, p. 9-438, 1999.

UNIÃO EUROPEIA. Conselho Europeu. Reunião extraordinária do Conselho Europeu. Conclusões. Bruxelas, 17-21 jul. 2020. Disponível em: https://www.consilium.europa.eu/media/45120/210720euco-final-conclusions-pt.pdf. Acesso em: 16 ago. 2020.

VENTURA, Deisy de Freitas Lima. Da emergência de um direito ao direito de emergência: o caso da pandemia da gripe A (H1N1) 2009-2010. 2012. Tese (Livre-docência) - Instituto de Relações Internacionais, Universidade de São Paulo, São Paulo, 2012. 
